\title{
Synthesis and Characterization of the Thermally Stable $\mathrm{Ho}(\mathrm{hfa})_{3}(\mathrm{tme})$
}

\author{
Seong-Joo Kang \\ Department of Chemistry Edtcation, Korea National Chwersity of Education, Cheongwon 363-791, Chungbuk, Korea \\ Received Hav 12, 2004
}

\begin{abstract}
Holmium $\beta$-diketonate complexes. Ho(hfa) ${ }_{3}$ (tme). has been prepared and characterized by IR. TGA. MS. and single-crystal X-ray analy'ses. This complex is air- and moisture-stable and most importantly has good volatility and thermal stability. Holmium atom binds to nine oxygen atoms. contributed by six oxygen atoms of three hfa ligands and three oxygen atoms of the tme ligand. The coordination polyhedron of Ho can be described as a distorted tricapped trigonal prism. Crystal data for $\mathrm{Ho}(\mathrm{lfa})_{2}(\mathrm{tme})$; orthorhombic $\mathrm{P} 2_{1} 2_{2} 2_{1}, \mathrm{a}=15.415(4)$. b= $13.17(2) . c=17.291(3) \AA . V=3496(1) \AA^{3}$.
\end{abstract}

Key Words : Holmium. Tricapped trigonal prism. hfa. CVD. 9-Coordination

\section{Introduction}

Metal $\beta$-diketonates find extensive use in chenical vapour deposition (CVD) process. which involve the formation of thin film for optical or microelectronic applications by CVD. The conventional lanthanide precursors for such films have several drawbacks. mostly notably in the high residue left in conmercial evaporators and poor stability to the atmosphere. ${ }^{1-3}$ A considerable diversity of $\beta$-diketonates and Lewis bases has been used to inprove such properties. We have described the synthesis and characterization of Lanthanide ( $\beta$-diketonate) (polyether) complex. The reactions of linear-polyether with the hydrated lanthanide $\beta$-diketonate complexes yielded the water-free lanthanide $\beta$-diketonate complexes showing thermal stability. ${ }^{4 \cdot 6}$ In this paper we report the reaction of branched-polyether (tme) with the hydrated holnium $\beta$-diketonate complex and discuss the structural characterization and thermal stability of $\mathrm{Ho}(\mathrm{hfa})_{3}$ (tmie).

\section{Experimental Section}

General procedures. All manipulations were performed under an inert atmosphere using Schlenk techniques. All solvents were distilled by standard techniques. Holmium oxide. Hhfa. MeI $\mathrm{NaH}$, and Triol were purchased from Aldrich and used as received ${ }^{7} \mathrm{Ho}(\mathrm{hfa})_{3}\left(\mathrm{H}_{2} \mathrm{O}\right)_{2}$ was prepared as previously described. FAB mass spectra were determined using a JOEL SX-102 spectrometer with 3-nitrobenzyl alcohol as the matrix material. Infrared spectra were recorded as $\mathrm{KBr}$ pellets on a Shimadzu FTIR-8501 model. TGA analysis was carried out on a SETARAM TGA-92 instrument.

Preparation of 1,1,1-tris(methoxymethyl)ethane (tme). The triol $(1.0 \mathrm{~g} .8 .15 \mathrm{mmol})$ was dissolved in $100 \mathrm{~mL}$ of THF. Sodium hydride (0.28 g. $8.2 \mathrm{mmol}$ ) was added and then the mixture was refluxed for 1d. 3-Methoxypropyl iodide ( $2.15 \mathrm{~g} .10 .1 \mathrm{mmol}$ ) dissolved in THF was added to the suspension, and the reaction mixture was refluxed for $l d$. The product mixture was distilled to give pure 1.1.1- tris(methoxymethyl)ethane. ${ }^{8}$ Yield: $0.65 \mathrm{~g}(49 \%)$. bp $152-$ $154^{\circ} \mathrm{C}$.

Preparation of $\mathrm{Ho}(\mathrm{hfa})_{3}$ (tme). Method 1. To a Schlenk flask containing $\mathrm{Ho}_{2} \mathrm{O}_{3}(0.20 \mathrm{~g} .0 .529 \mathrm{mmol})$ and the $(0.172$ g. $1.06 \mathrm{~mm}$ ) $)$ were added $20 \mathrm{~mL}$ of toluene and Hhfa $(0.45$ $\mathrm{mL}, 3.18 \mathrm{mmol}$ ). After stirring and refluxing for $2 \mathrm{~d}$ the remaining holmium oxide was filtered off. The solvent was removed in wacho to yield yellow precipitates. Slow evaporation of hot dilute hexane solution gave crystals suitable for x-ray crystallography. Yield: $0.58 \mathrm{~g} .58^{\circ} \mathrm{C}$.

Method 2. To a benzene solution $(10 \mathrm{~mL})$ of $\mathrm{Ho}(\mathrm{hfa})_{3-}$ $\left(\mathrm{H}_{2} \mathrm{O}\right)_{2}(0.22 \mathrm{~g}, 0.268 \mathrm{~mm}$ ol) was added the $(0.043 \mathrm{~g}, 0.268$ mmol). After stirring and refluxing for Id the volume of solution was reduced to half. Yield: $0.21 \mathrm{~g} .83 \%$. mp: 112 $116^{\circ} \mathrm{C}$. IR (KBr, cm${ }^{-1}$ ): 3380 (w). 2920 (w). 1640 (s). 1540 (m), 1510 (m), 1480 (s). 1410 (w), 1340 (w). 1240 (s), 1190

Table 1. Crỵstal Data and Structure Refinement for Ho(hfa)s(tme)

\begin{tabular}{|c|c|}
\hline fonmula & $\mathrm{C}_{23} \mathrm{H}_{21} \mathrm{~F}_{18} \mathrm{HoO}_{9}$ \\
\hline fiw & 948.33 \\
\hline $\mathrm{T}\left({ }^{\circ} \mathrm{C}\right)$ & $20(2)$ \\
\hline wavelength, $A$ & 0.71070 \\
\hline space group & $\mathrm{P} 2_{1} 2_{1} 2_{1}$ \\
\hline a, $\AA$ & $15.415(4)$ \\
\hline b. $\AA$ & $13.117(2)$ \\
\hline$c, \AA$ & $17.291(3)$ \\
\hline $\mathrm{V}, \AA^{3}$ & $3496.2(12)$ \\
\hline 2 & 4 \\
\hline$\rho_{\text {salud }} \mathrm{gcm}^{-3}$ & 1.802 \\
\hline$\mu(\mathrm{Mo} \mathrm{K} \alpha), \mathrm{cm}^{-1}$ & 24.02 \\
\hline no. of rflns colletd & 3555 \\
\hline no. of indep rtlns & $3058[\mathrm{R}(\mathrm{int})=0.0166$ \\
\hline no. of params & 457 \\
\hline GOF on $\mathrm{F}^{2}$ & 1.055 \\
\hline final $R$ indices $[I>2 \sigma(I)]$ & $\mathrm{R} 1=0.0452, \mathrm{wR} 2=0.1269$ \\
\hline$R$ indices (all data) & $\mathrm{R} 1=0.0566, \mathrm{H} 2=0.1402$ \\
\hline largest diff. peak and hole, eA $\AA^{3}$ & +1.031 and -1.009 \\
\hline
\end{tabular}

${ }^{a} \mathrm{R} 1=\Sigma\left|F_{\mathrm{n}}\right|-\left|F_{\mathrm{C}}: \Sigma\right| F_{\mathrm{n}}, \mathrm{w} \mathrm{R} 2=\left\{\Sigma w\left(F_{0,}{ }^{2}-F_{C}{ }^{2}\right\}^{1} \sum \Sigma_{w F_{0}}\right\}^{4 / 2}$. where $w=$ l: $\left\{\sigma^{2} F_{0}^{2}+(0.0786 P)^{2}+5.28 P\right\}$ and where $p=\left\{\operatorname{Max}\left(F_{0}^{2}, 0\right)-2 F_{c}{ }^{2}\right\} 3$ 
Table 2. Selected Bond I engths [A] and Angles [deg] for Hoth a a s(tme)

\begin{tabular}{|c|c|c|c|}
\hline $\mathrm{Ho}-\mathrm{O}(1)$ & $2.341(9)$ & $\mathrm{Ho}-\mathrm{O}(2)$ & $2.42(2)$ \\
\hline $\mathrm{Ho}-\mathrm{O}(3)$ & $2.378(9)$ & $\mathrm{Ho}-\mathrm{O}(4)$ & $2.273(13)$ \\
\hline $\mathrm{Ho}-\mathrm{O}(5)$ & $2.338(12)$ & $\mathrm{Ho}-\mathrm{O}(6)$ & $2.390 \times 8$ \\
\hline $\mathrm{Ho}-\mathrm{O}(7)$ & $2.376(12)$ & $\mathrm{Ho}-\mathrm{O}(8)$ & $2.502(11)$ \\
\hline $\mathrm{Ho}-\mathrm{O}(9)$ & $2.458(7)$ & $O(1)-C(2)$ & $1.26(2)$ \\
\hline$O(2)-C(4)$ & I.I9(2) & $O(3)-C(7)$ & $1.26(2)$ \\
\hline$O(4)-C(9)$ & $1.28(2)$ & $O(5)-C(12)$ & $1.25(2)$ \\
\hline$O(6)-C(14)$ & $1.28(2)$ & $O(7)-C(18)$ & $1.45(2)$ \\
\hline$O(7)-C(19)$ & $1.44(2)$ & $O(8)-C(20)$ & $1.41(3)$ \\
\hline$O(8)-C(21)$ & $1.41(2)$ & $O(9)-C(22)$ & $1.39(2)$ \\
\hline$O(9)-C(23)$ & $1.42(2)$ & $C(1)-C(2)$ & $1.64(3)$ \\
\hline$C(2)-C(3)$ & $1.35(3)$ & $C(3)-C(4)$ & $1.37(2)$ \\
\hline$C(4)-C(5 A)$ & $1.26(4)$ & $C(5)-C(5 \Lambda)$ & $1.53(7)$ \\
\hline$C(6)-C(6 \wedge)$ & $0.9(2)$ & $C(6)-C(7)$ & $1.6(2)$ \\
\hline$C(6 \wedge)-C(7)$ & $1.47(4)$ & $C(7)-C(8)$ & $1.37(2)$ \\
\hline$C(8)-C(9)$ & $1.39(3)$ & $C(9)-C(10)$ & $1.75(4)$ \\
\hline$C(1 I)-C(12)$ & $1.54(3)$ & $C(12)-C(13)$ & $1.39(2)$ \\
\hline$C(13)-C(14)$ & $1.40(3)$ & $C(14)-C(15)$ & $1.47(2)$ \\
\hline$C(16)-C(17)$ & $1.56(2)$ & $C(16)-C(18)$ & $1.55(4)$ \\
\hline$C(16)-C(20)$ & $1.38(4)$ & $C(16)-C(22)$ & $1.48(2)$ \\
\hline $\mathrm{O}(1)-\mathrm{Ho}-\mathrm{O}(2)$ & $69.8(4)$ & $\mathrm{O}(1)-\mathrm{Ho}-\mathrm{O}(3)$ & $71.4(4)$ \\
\hline $\mathrm{O}(1)-\mathrm{Ho}-\mathrm{O}(4)$ & $73.6(4)$ & $\mathrm{O}(1)-\mathrm{Ho}-\mathrm{O}(5)$ & $73.9(4)$ \\
\hline $\mathrm{O}(1)-\mathrm{Ho}-\mathrm{O}(6)$ & $132.9(3)$ & $\mathrm{O}(1)-\mathrm{Ho}-\mathrm{O}(7)$ & $142.4(4)$ \\
\hline $\mathrm{O}(1)-\mathrm{Ho}-\mathrm{O}(8)$ & $138.4(4)$ & $\mathrm{O}(1)-\mathrm{Ho}-\mathrm{O}(9)$ & $94.5(3)$ \\
\hline $\mathrm{O}(2)-\mathrm{Ho}-\mathrm{O}(3)$ & $120.3(4)$ & $\mathrm{O}(2)-\mathrm{Ho}-\mathrm{O}(4)$ & $133.3(5)$ \\
\hline $\mathrm{O}(2)-\mathrm{Ho}-\mathrm{O}(5)$ & $69.2(5)$ & $\mathrm{O}(2)-\mathrm{Ho}-\mathrm{O}(6)$ & $126.3(5)$ \\
\hline $\mathrm{O}(2)-\mathrm{Ho}-\mathrm{O}(7)$ & $72.7(4)$ & $\mathrm{O}(2)-\mathrm{Ho}-\mathrm{O}(8)$ & $133.5(5)$ \\
\hline $\mathrm{O}(2)-\mathrm{Ho}-\mathrm{O}(9)$ & $69.1(6)$ & $\mathrm{O}(3)-\mathrm{Ho}-\mathrm{O}(4)$ & $71.8(4)$ \\
\hline $\mathrm{O}(3)-\mathrm{Ho}-\mathrm{O}(5)$ & $136.3(4)$ & $\mathrm{O}(3)-\mathrm{Ho}-\mathrm{O}(6)$ & $113.4(5)$ \\
\hline $\mathrm{O}(3)-\mathrm{Ho}-\mathrm{O}(7)$ & $129.3(4)$ & $\mathrm{O}(3)-\mathrm{Ho}-\mathrm{O}(8)$ & $67.0(4)$ \\
\hline $\mathrm{O}(3)-\mathrm{Ho}-\mathrm{O}(9)$ & $70.7(5)$ & $\mathrm{O}(4)-\mathrm{Ho}-\mathrm{O}(5)$ & $73.5(3)$ \\
\hline $\mathrm{O}(4)-\mathrm{Ho}-\mathrm{O}(6)$ & $65.1(4)$ & $\mathrm{O}(4)-\mathrm{Ho}-\mathrm{O}(7)$ & $138.1(5)$ \\
\hline $\mathrm{O}(4)-\mathrm{Ho}-\mathrm{O}(8)$ & $93.2(5)$ & $\mathrm{O}(4)-\mathrm{Ho}-\mathrm{O}(9)$ & $142.5(6)$ \\
\hline $\mathrm{O}(5)-\mathrm{Ho}-\mathrm{O}(6)$ & $73.6(4)$ & $\mathrm{O}(5)-\mathrm{Ho}-\mathrm{O}(7)$ & $94.3(4)$ \\
\hline $\mathrm{O}(5)-\mathrm{Ho}-\mathrm{O}(8)$ & $140.9(5)$ & $\mathrm{O}(5)-\mathrm{Ho}-\mathrm{O}(9)$ & $138.2(6)$ \\
\hline $\mathrm{O}(6)-\mathrm{Ho}-\mathrm{O}(7)$ & $73.0(4)$ & $\mathrm{O}(6)-\mathrm{Ho}-\mathrm{O}(8)$ & $67.5(5)$ \\
\hline $\mathrm{O}(6)-\mathrm{Ho}-\mathrm{O}(9)$ & $132.2(3)$ & $\mathrm{O}(7)-\mathrm{Ho}-\mathrm{O}(8)$ & $71.0(4)$ \\
\hline $\mathrm{O}(7)-\mathrm{Ho}-\mathrm{O}(9)$ & $70.5(5)$ & $\mathrm{O}(8)-\mathrm{Ho}-\mathrm{O}(9)$ & $72.0(5)$ \\
\hline$C(2)-O(1)-\mathrm{Ho}$ & $133.4(10)$ & $\mathrm{C}(4)-\mathrm{O}(2)-\mathrm{Ho}$ & $134.8(12)$ \\
\hline $\mathrm{C}(7)-\mathrm{O}(3)-\mathrm{Ho}$ & $135.4(11)$ & $\mathrm{C}(9)-\mathrm{O}(4)-\mathrm{H}_{0}$ & $134.3(11)$ \\
\hline $\mathrm{C}(12)-\mathrm{O}(5)-\mathrm{Ho}$ & $135.9(12)$ & $\mathrm{C}(14)-\mathrm{O}(6)-\mathrm{Ho}_{0}$ & $128.3(11)$ \\
\hline $\mathrm{C}(18)-\mathrm{O}(7)-\mathrm{Ho}$ & $130.1(12)$ & $\mathrm{C}(19)-\mathrm{O}(7)-\mathrm{Ho}$ & $115.7(9)$ \\
\hline $\mathrm{C}(20)-\mathrm{O}(8)-\mathrm{Ho}$ & $126(2)$ & $\mathrm{C}(21)-\mathrm{O}(8)-\mathrm{Ho}_{0}$ & $122.0(12)$ \\
\hline $\mathrm{C}(22)-\mathrm{O}(9)-\mathrm{Ho}$ & $127.9(8)$ & $\mathrm{C}(23)-\mathrm{O}(9)-\mathrm{Ho}$ & $118.4(8)$ \\
\hline
\end{tabular}

(s). $1130(\mathrm{~s}), 1080(\mathrm{~m}), 1060(\mathrm{w}), 800(\mathrm{w}), 655(\mathrm{w})$. MS ( $\mathrm{FAB} ; \mathrm{m} / \mathrm{z}$ (fragment)): 885 ( $\mathrm{P}$-tme- $\left.\mathrm{CF}_{3} \mathrm{CH}_{3} \mathrm{tfa}\right), 732$ (Ptme $\left.+\mathrm{CH}_{3}+\mathrm{CH}_{3}\right), 671$ (P-tme-hfa+2 $\left.\mathrm{CH}_{3} \mathrm{OCH}\right), 553$ (P-tmehfa), 529 (P-tme-hfa-C $F_{2}$ ).

X-ray crystal analysis. Crystallographic parameters and information related to data collection and structural refinements for the complex are given in Table 1. The data were corrected for Lorentz and polarization effects. Absorption effects were corrected by the empirical $\phi$-scan method. The structure were solved by the Patterson method (SHFI.XS86 ) and were refined by full-matrix least squares techniques (SHГL,XL,-93). All non-hydrogen atoms were refined anisotropically and the positions of hydrogen atoms were idealized, assigned isotropic thermal parameters $\left[\mathrm{U}_{i s 0}(\mathrm{H})=\right.$ $\left.1,2 \mathrm{U}_{\mathrm{ey}}(\mathrm{C})\right]$ and allowed to ride on the parent carbon atoms. All calculations were carried out on the personal computer with use of the SHГI.XS-86 and SHГI.XI.-93 programs. ${ }^{9.10}$ Selected bond lengths and angles are given in Table 2 .

\section{Results and Discussion}

Preparation. Ho(hfa) (tme) complex has been synthesized from two different pathways summarized by (1) and (2). $\mathrm{Ho}(\mathrm{l} f \mathrm{f})_{3}$ (tme) was obtained by the reaction of $\mathrm{H}_{2} \mathrm{O}_{3}$ with Hhfa and tme in toluene (1). In addition this compound was also synthesized from the reaction of $\mathrm{Ho}(\mathrm{h} f \mathrm{a})_{3}\left(\mathrm{H}_{2} \mathrm{O}\right)_{2}$, with tme ligand (2).

$$
\begin{aligned}
& \mathrm{Ho}_{2} \mathrm{O}_{3}-6 \mathrm{Hhfa}+2 \text { tme } \rightarrow 2 \mathrm{Ho}(\mathrm{hfa})_{3}(\text { tme })-3 \mathrm{H}_{2} \mathrm{O} \\
& \mathrm{Ho}(\mathrm{hfa})_{3}\left(\mathrm{H}_{2} \mathrm{O}\right)_{2}+\text { tme } \rightarrow \mathrm{Ho}(\text { hfa })_{3}(\text { tme })+2 \mathrm{H}_{2} \mathrm{O}
\end{aligned}
$$

This compound has a low melting point of $112-116^{\circ} \mathrm{C}$ and sublimes intact. More importantly, this compound displays excellent stability to both moisture and oxygen, with negligible decomposition over a period of months in the open laboratory. We have studied for the reaction of $\mathrm{Ho}(\mathrm{hfa})_{s^{-}}$ $\left(\mathrm{H}_{2} \mathrm{O}\right)_{2}$ with several polyether ligands.

$\mathrm{Ho}(\mathrm{hfa})_{3}\left(\mathrm{H}_{2} \mathrm{O}\right)_{2}+$ polyether (monoglyme, diglyme, tme) $\longrightarrow \mathrm{Ho}(\text { hfa })_{3}$ (polyether) $+2 \mathrm{H}_{2} \mathrm{O}$

The reactions of $\mathrm{Ho}(\mathrm{hfa})_{3}\left(\mathrm{H}_{2} \mathrm{O}\right)_{2}$ with monoglyme, diglyme, and tme ligand yield polyether-coordinated holmium complexes. The polyether ligand acts as a partitioning agent. removing the coordinated water completely.

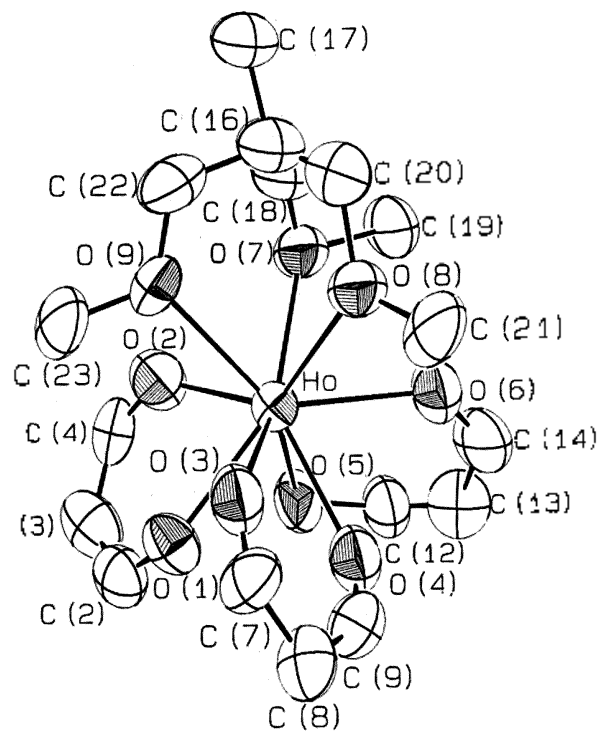

Figure 1. ORlLP drating of the crystal structure of I lo(hta) $)_{3}$ (tme) shoving the atomic labelling scheme and thermal ellipsoidal at $50 \%$ level. 


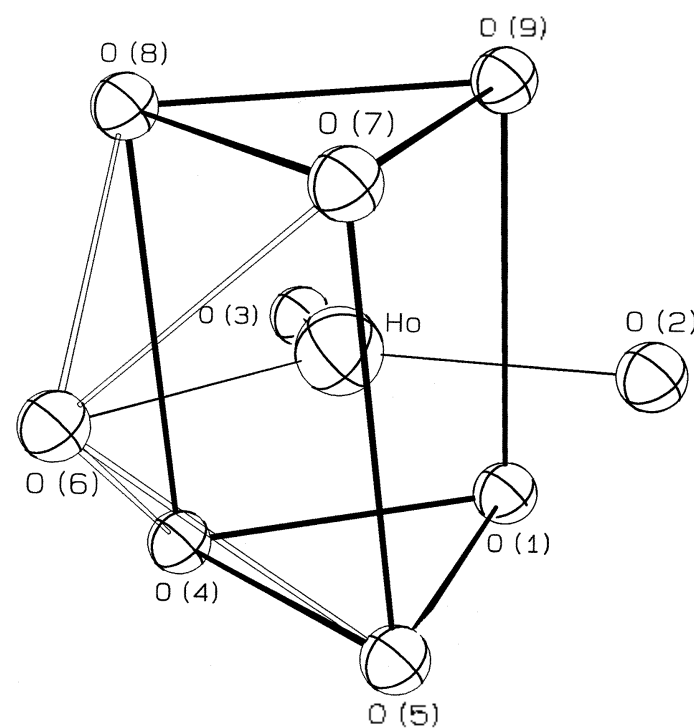

Figure 2. Coordination polyhedron of I lo(hta) (tme) showing the Ho environment.

Structural description of $\mathbf{H o}(\mathbf{h f a})_{3}$ (tme). The molecular structure of $\mathrm{Ho}(\mathrm{hfa})_{3}(\mathrm{tme})$ is shown in Figure 1, with the $C F_{3}$ groups of hfa ligand have been onitted for clarity. Holmium atom binds to nine oxygen atoms, contributed by six oxygen atoms of three hfa ligands and three oxygen atoms of the tme ligand.

The two possible ground-state geometries for ninecoordination polyhedra are the tricapped trigonal prism with $D_{\text {sh }}$ symmetry and the monocapped square antiprism with $\mathrm{C}_{4 \mathrm{r}}$ symmetry. ${ }^{1-13}$ The coordination polyhedron of Ho cam be described as a distorted tricapped trigonal prism, with the top represented by $[O(7), O(8), O(9)]$ plane, the bottom depicted by the $[O(1), O(4), O(5)]$, and the face capped by $[O(2), O(3), O(6)]$ (see Figure 2).

The $\mathrm{Ho}_{\mathrm{O}} \mathrm{O}$ bond length of $\mathrm{Ho}(\mathrm{hfa})_{\mathrm{s}}$ (tme) can be classified by three group; one from neutral tme ligand and two from anionic hfa ligands. The average Ho-O bond distance of hfa ligands $(2.36[2] \AA)$ is shorter than that of the tme ligand (2.45[1] $\AA$ ) (lable 2). As mentioned, the Ho-O bond length of hfa ligands falls into two distinctly different groups; those formed the trigonal plane (average 2.32[1] $\AA$ ) and those capped the prismatic faces (average $2.40[1] \AA$ ). The coordination number and the size of the central metal affect the bond length of the metal-coordinated atom. The average Ho$\mathrm{O}$ (of hfa) bond length for the nine coordinated Ho(hfa $)_{3}$ tme $\left[\begin{array}{ll}2.36 & \bar{A}\end{array}\right]$ is longer than that for the eight coordinated $\mathrm{Ho}(\mathrm{hfa})$ : monoglyme $[2.31 \AA]$ ( lable 3 ). The average $\mathrm{Ln}-\mathrm{O}$ (of hfa) bond distance ( $\mathrm{Ln}=\mathrm{La}, \mathrm{Eu}, \mathrm{Ho}$ ) is in the order of $\mathrm{La}-\mathrm{O}>\mathrm{Eu}-\mathrm{O}>\mathrm{Ho}-\mathrm{O}$. These differences are in part due to the significantly different ionic radii of the metal centers involved. The polyhedron geometry of $\mathrm{Ho}(\mathrm{hfa})_{i}$ tme is a distorted tricapped trigonal prism while $\mathrm{La}(\mathrm{hfa})_{3}$ 'diglyme and $E$ u(hfa) $)_{\hat{s}} \cdot d i g l y m e$ adapted a capped square antiprism. This geometric difference might be due to the role of polyether. The linear diglyme polyether gives the capped square antiprism while a branched tme forms the tricapped
Table 3. The Average I englhs of I n-O(of hla). Coordination Number and Gicometry for the Ln-O(of hfa)(polyether) Complexes

\begin{tabular}{|c|c|c|c|}
\hline Comp. & $\begin{array}{l}\text { Average lengliss } \\
\text { of } 1 \text { n-O(of hla) }\end{array}$ & $\begin{array}{l}\text { Coordination } \\
\text { number }\end{array}$ & Geometry \\
\hline Io(hfa) monoglyme & 2.3111 & 8 & scl. an. ${ }^{*}$ \\
\hline lfo(hfa) $)_{3} \cdot \operatorname{lm} e$ & $2.36 \mid 1]$ & 9 & cap. tri, pr. \\
\hline 1.a(h) $\left.f_{1}\right)_{s}$ diglyme & |וי|ון & 9 & cap sq. an. \\
\hline lu(h)tars diglyme & $2.40 \mid 11$ & 9 & cap. sq. an. \\
\hline
\end{tabular}

‘c. an.: square antiprism. cap. tri. pr.: tricapped trigoral prism. cap. sq. at3.: capped square antiprism

Table 4. Bond Separation $|A|$ and $A$ ngles $\mid$ degl for $\mathrm{Ho}(\mathrm{h} f \mathrm{a})_{3}(\mathrm{tme})$

\begin{tabular}{|c|c|c|c|}
\hline$(0(1)-O(4)$ & 2.76 & $(x)(1)-()(5)$ & 2.81 \\
\hline$O(1)-O(9)$ & 3.52 & $O(4)-O(5)$ & 2.76 \\
\hline$O(4)-O(8)$ & 3.47 & $O(5)-0(7)$ & 3.46 \\
\hline $0(7)-O(8)$ & 2.83 & $O(7)-O(9)$ & 2.79 \\
\hline$O(8)-0(9)$ & 2.91 & $O(4)-O(7)$ & 4.34 \\
\hline$O(5)-O(8)$ & 4.56 & $O(2)-O(3)$ & 4.16 \\
\hline $0(2)-O(6)$ & 4.29 & $(0(3)-0(6)$ & 3.99 \\
\hline$O(4)-O(6)$ & 2.51 & $O(5)-0(6)$ & 2.83 \\
\hline$O(7)-O(6)$ & 2.84 & $O(8)--O(6)$ & 2.72 \\
\hline$O(1)-0(4)-0(5)$ & 61.2 & $O(1)-0(5)-0(4)$ & 59.4 \\
\hline$O(4)-0(1)-0(5)$ & 59.4 & $0(7)-0(8)-0(9)$ & 58.9 \\
\hline$O(7)-0(9)-0(8)$ & 59.5 & $O(8)-0(7)-0(9)$ & 61.6 \\
\hline$(3(4)-0(5)-0(7)$ & 87.7 & $O(4)-0(8)-0(7)$ & 86.5 \\
\hline$(3(5)-0(4)-0(8)$ & 93.4 & $0(5)-0(7)-0(8)$ & 92.4 \\
\hline$(3(1)-0)(9)-()(7)$ & 87.7 & $0(1)-0(9)-0(8)$ & 86.5 \\
\hline$C(9)-0(1)-O(4)$ & 93.4 & $0(9)-0(1)-0(5)$ & 92.4 \\
\hline
\end{tabular}

trigonal prism.

The average $\mathrm{O}-\mathrm{Ho}_{\mathrm{O}} \mathrm{O}$ angle of the same hat ligand is $71.7[2]^{\circ}$ and the corresponding angle of the tme ligand is $71.1[5]^{3}$. The average $\mathrm{O}-\mathrm{Ho}-\mathrm{O}$ angle among capping oxygen atoms, e.g. $\mathrm{O}(2)-\mathrm{Ho}-\mathrm{O}(3)$, is $120[1]^{\circ}$ whereas that locating oxygen atoms in a trigonal plane, e.g. $\mathrm{O}(1)-\mathrm{Ho}-\mathrm{O}(4)$, is $73.7[3]^{\circ}$.

The average $\mathrm{O}-\mathrm{O} \mathrm{O}$ separation in trigonal planes, $e \cdot g \cdot \mathrm{O}(\mathrm{l})--$ $O(5)$, is $2.81 \AA$ while that among capping oxygen atoms, e.g. $\mathrm{O}(2)-\mathrm{O}(3)$, is $4.15 \AA$ (lable 4$)$. The length of rectangle is about $2.81 \times 3.48 \AA$. The mean plane separation between two trigonal planes is about $3.48 \AA$ and two trigonal planes are nearly parallel. There are two type's dihedral angles, one between squares planes and the other between square and trigonal plane. The former, e.g. $O(1)-O(5)-O(7)-O(9)$ and $O(4)-O(5)-O(7)-O(8)$, is close to 60 and the latter, e.g. $O(1)-$ $O(5)-O(7)-O(9)$ and $O(7)-O(8)-O(9)$, is nearly orthogonal.

The average $\mathrm{C}-\mathrm{O}$ distance of hfa ligands is $1.25[2] \dot{A}$ whereas the corresponding bond length of the tme is 1.42 [3] $\dot{A}$. The $\mathrm{C}-\mathrm{C}$ bond distances of the hfa ligands fall into two distinctly different groups: $\mathrm{C}(1)-\mathrm{C}(2)$ and $\mathrm{C}(4)-\mathrm{C}(5), 1.51[2]$ $\AA$ and $\mathrm{C}(2)-\mathrm{C}(3)$ and $\mathrm{C}(3)-\mathrm{C}(4), 1.39[2] \AA$. The average $\mathrm{C}-\mathrm{C}$ bond distances of the tme ligand is about 1.50[2] $\AA$. There are intra $(\mathrm{CH}-\mathrm{O})$ and inter $(\mathrm{CH}-\mathrm{F})$ molecular hydrogen bonds.

Other properties. Jo evaluate the utility of $\mathrm{Ho}(\mathrm{hfa})_{3}$ (tme) 


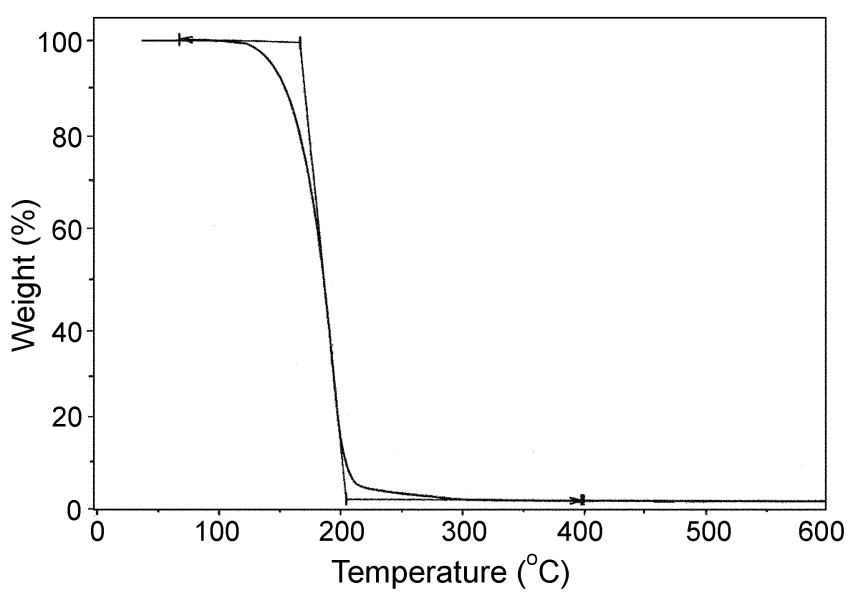

Figure 3. TGA diagram of $\mathrm{Ho}(\mathrm{hfa})_{3}(\mathrm{tme})$.

as precursors for CVD, the thermogravic behavior of the complexes has been investigated by TGA over the temperature range $30-600^{\circ} \mathrm{C}$. The TGA curve of $\mathrm{Ho}(\mathrm{hfa})$ (tme) is reported in Figure 3. The TGA plot shows a singular sublimation step in the $110-210^{\circ} \mathrm{C}$ temperature range and no weight loss after $290^{\circ} \mathrm{C}$.

This indicates that $\mathrm{Ho}(\mathrm{hfa})_{3}(\mathrm{tme})$ is a stable potential precursor which delivers the homoleptic tme complex into the gas phase easily. A tinal residue of $1.56 \%$ indicates an almost quantitative sublimation. This might be attributed to the highly electronegative $\mathrm{CF}_{\mathrm{s}}$ group of the hfa ligand and therefore no loss of the tme during TGA experiment. IR spectra of $\mathrm{Ho}$ (hfa) (tme) show characteristic bands for the $\beta$ diketonate with strong absorption bands for carbonyl group at $1640 \mathrm{~cm}^{-1}$. The $C-F$ stretching frequencies of hfa ligand fall in the same regions as those of the $\mathrm{C}-\mathrm{O}$ for the tme. In the MS spectrum of $\mathrm{Ho}(\mathrm{hfa})_{3}$ (tme), prominent signals correspond to the fragments (P-tme-hfa), (P-tme-hfa-CF $)$, (P-tme-CF $\left.\mathrm{CH}_{3}+\mathrm{CH}_{3}-\mathrm{tfa}\right),\left(\mathrm{P}-\mathrm{tme}+\mathrm{CF}_{3}+\mathrm{CH}_{3}\right),(\mathrm{P}-\mathrm{t}$ ene-hat + $2 \mathrm{CH}_{3} \mathrm{OCH}_{3}$ ). Molecular ion peak is not observed.

\section{Conclusions}

The thermally stable $\mathrm{Ho}(\mathrm{hfa})_{\text {it }}$ (tme) complex was readily synthesized from the reaction of $\mathrm{Ho}(\mathrm{hfa})_{3}\left(\mathrm{H}_{2} \mathrm{O}\right)_{2}$ with tme.
The product has been shown to be air- and moisture-stable with sublime intact. The X-ray structural characterization of Ho(bfa) (tme) shows that holmium metal ion is saturated with nine coordinates. The polyhedron geometry of

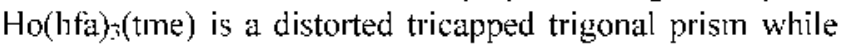

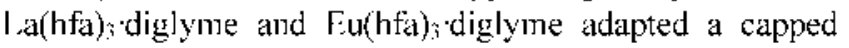
square antiprism. This geometric difference might be due to the role of polyether.

Supporting Information Available. Crystallographic data for the structure reported here have been deposited with the Cambridge Crystallographic Data centre (Deposition No. CCDC-241715). The data can be obtained free of charge via wwicclc.cam.ac.uk/conts/retrieving.hml (or from the CCDC, 12 Union Road, Cambridge CB2 1Г7., UK; fax:-441223 336033; e-mail; deposit(d)cedc.cam.ac.uk).

\section{References}

1. Drake. S. R.: Hursthouse. M. B.: Malik. K. M. A.: Miller. S. A. S.: Otway. D. J. horg. (hem. 1993. 32. 4464.

2. Drakc. R.: I yous A, I ., Otway. D, J.: Slawin. A, M. 7.: Williams. D. J. J. Chem. Soc., Dalton froms, 1993. 2379.

3. (ileires. A.: [enain]. S.: Medus. [3.: [lovnanian. N.: Miele. I).: Foulon. J.-D. horg. (him. Acta 1993. 269. 47.

4. Kang. S.-J.: Jung. Y. S.: Sohn. Y. S. Bull Koreon Chent. Soc. 1997. 18.75 .

5. Kang. S.-J.: Jung. Y. S.: Suh. I.-I., Buh. Aroweon Chem. Soc. 1999. 20.95.

6. Kang. S.-I. L ee. S. K. Bth. Korean Chem. Soc. 20113. 24. 535.

7. Abbreviations used in this paper include: Hhfa. lexafluoroacetylacetone: hla. anion of Hhla: Jriol. 2-(hydroxymethyl)-2methyl-1.3-proparediol or 1.1.1-tris(hydrosymethy])thane: tme. I.1.I-Tris(methoxymethyl)ethane: 4-Mothoxymethyl-4-methyl2.6-dioxiaheptanc

8. Dalle. I.: Fredriksen, S. 13. Aco Chem. Soumd 1992. 46. 27I.

9. Sheldrick. G. M. In SIIEIXS-86. A l'rogram for Structure Detemination: Liviversily of Gottingen: Germany. 1986.

10. Sheldrick. G. M. It SHELXI-93, A Program for Structure Refinement: Liniversity of (iottingen: (ismany. 1993.

11. Abrabans, S. C.: Ginsbere. A. P.: Knox. K. Inorg. Chem. 1964. 3. 558.

12. Santos. I. C.: Nogueira. H. I.: l'ac. F. A.: Ferreira R. A.: Carlos. L. D.: Klinowshi. J.: Irindade. 1. Edt. J. howg. (hem. 2003. 3609 .

13. Kim, S.-J Park, S.: Yim, S. Bull. Norew chem. Sox 2004, 25. 485. 